\title{
An Explorative Qualitative Study on Pharmacist Active Engagement Approach in Primary Healthcare Diabetic Education
}

\author{
Selvakumari Selvadurai, ${ }^{1,2}$, Mohd Makmor-Bakry ${ }^{1 *}$, Adliah Mhd Ali ${ }^{1}$
}

1. Faculty of Pharmacy, Universiti Kebangsaan Malaysia, 50300 Kuala Lumpur.

2. Bahagian Farmasi, Jabatan Kesihatan Wilayah Persekutuan Kuala Lumpur \& Putrajaya, 50590 Kuala Lumpur.

\begin{tabular}{l} 
Info Article \\
\hline Submitted: $26-03-2020$ \\
Revised: $10-07-2020$ \\
Accepted: 01-09-2020 \\
*Corresponding author \\
Mohd Makmor Bakry \\
Email: \\
mohdclinpharm@ukm.edu. \\
my
\end{tabular}

\section{INTRODUCTION}

The prevalence of diabetes mellitus increases yearly and becoming the major burden to health system and financial (Guariguata et al., 2014). Failure to include patients' beliefs, preferences, and expectations as part of the management consideration was the major cause of patients' non-adherence to medications (Wilson et al., 2010). In Malaysia, non-adherence to diabetes medication therapy has been reported at 53\% (Sufiza et al., 2013).This issue further contributed to wastage of health resources. Effectiveness and efficiency of healthcare can be enhanced if patient actively participates into their own health management (Zuckerman et al., 2013). This will lead to improved health outcomes and lower healthcare costs. Holistic approach in treating patient and the implementation of engaging patient-centred communication enhances the trust between patient and pharmacist (Naughton, 2018). Self-management education support that includes problem-solving and shared decision-making skills development will be the responsibility of primary care providers in the future for chronic care (Graffigna et al., 2014). Patients with good attitude have higher confidence to make an informed decisions with pharmacist consultation ( $\mathrm{Ng}$ et al., 2018). Nevertheless, healthcare systems often fails 
to deliver effective interventions that are able to sustain patient engagement and bridge the gap between patient's health and diabetes care (Shortell, 2013).

Healthcare providers should respect the wishes and beliefs of patients in deciding the treatment plan. This is a process between healthcare providers and patients to promote open information exchange. Healthcare providers should treat the patients as equal partners in making decisions, developing a therapeutic alliance and mutual understanding (Snowden et al., 2014). In Malaysia, Diabetes Medication Adherence Clinics (DMTACs) runs by pharmacists were established in 2004. The counselling sessions were mainly focused on medications and adherence. It was suggested that the pharmacists can utilised active engagement approach or concordance in their counselling session to further enhance the effectiveness of the DMTAC counselling (Ministry of Health Malaysia, 2014). Findings from this study may be beneficial for counseling pharmacists and other related healthcare services, such as dietitian, to adapt the active engagement practice. Therefore, the objective of the present study was to explore the various elements that may affect the pharmacist-patient active engagement during the current DMTAC counselling sessions in type 2 diabetes patients in primary healthcare setting.

\section{MATERIAL AND METHODS Sample and design}

This study received ethical approval from Medical Research and Ethics Committee of Ministry of Health Malaysia (NMRR-18-3789-45443 (IIR)). An interpretative approach employing qualitative face-to-face interview was utilised. Purposive sampling strategy was used to recruit the pharmacists and the patients. This method is frequently used because it can elicit and explore the experiences of the patients and pharmacists with a specific phenomenon required. Five government health clinics from Kuala Lumpur were chosen for the study. Ten pharmacists and 15 patients were included in the study. Data was collected until saturation was achieved. Patients aged of 18 years and above and diagnosed with type 2 DM for at least two years, a latest HbA1c within the last 6 months, emotionally and physically capable of undergoing a clinical-psychological research interview, and able to converse in Malay or English were selected. The pharmacists recruited in this study, have been actively involved in counseling under the DMTAC program. Patients and pharmacists were consented before interview. The data collected to identify similarities and differences from pharmacists and patients perspective of healthcare engagements with patients.

\section{Data collection}

A semi-structured guide was used in this indepth interview. The guide consisted of openended probing questions related to the DMTAC counselling session on how they feel about the sessions in terms of approach, treatment plans, communication skills, and other related questions exploring the pharmacist and patient engagement. The interview guide for the patients was intended to explore in-depth patient's experiences, concerns and care during the counselling with the pharmacists. The DMTAC pharmacists were asked from the pharmacist's perspectives. Patients and pharmacists were interviewed to obtain data from both perspectives and triangulated to reduce potential biases. The interview guide was piloted on two participants to assess the feasibility of the interview guide. After the piloting, the interview guide was further refined to meet the objectives of the study (Table I).

The first researcher (SS) conducted all interviews. The interviews were conducted face-toface in the counselling room. The researcher approached the patients at the end of their counselling session with the pharmacist. The interview questions were translated from English to Malay by SS and further checked, and validated by MMB and AMA to ensure that there were no discrepancies in the translation. Probing questions were used to obtain better output from the patients and pharmacists. The interviews were conducted until data saturation was reached for the patients and pharmacists (Saunders et al., 2018). Each interview lasted about an average of 40 minutes. All interviews were audio-recorded and transcribed verbatim. They were then read and checked by two other researchers (MMB and AMA) to ensure the accuracy and fluency. Any potential misinterpretations were clarified and agreed. All the interviews were given a numbered pseudonym to maintain confidentiality.

\section{Data analysis}

The data obtained from the interviews were thematically analysed by employing line-by-line coding and inductive reading of the transcripts. The transcripts were independently coded and summarised by the first researcher (SS). 
Table I. Interview guide for patients and pharmacists

\begin{tabular}{l} 
No Patients \\
\hline 1 How does the pharmacist start the counseling \\
session with you? \\
2 How does pharmacist treat you during your \\
counselling sessions? Take time to bond with \\
you? \\
3 Please explain, how does the pharmacists' \\
communicate with you? \\
4 Does the pharmacist re-assess your medication \\
understanding? What type of questions that the \\
pharmacists ask you to assess your \\
understanding? \\
5 How is the pharmacist's attitude towards you \\
when facing you during the counselling session? \\
4 How does the pharmacist encourage you to \\
share ideas, discuss your feelings about the \\
treatment plan and medications? \\
5 Are the pharmacist's sensitive towards you
\end{tabular}

5 Are the pharmacist's sensitive towards you when giving information and instructions to you?

6 Do the pharmacists support or accept your believe relating to diabetes and its medications? If yes, Why? If no why

7 Whose decision is the most important during counselling? Is it yours or the pharmacists? Why?

8 Are you able to discuss and agree upon a treatment plan with your pharmacists to reach the desired effect of treatments (mutua agreement)?

9 Does the pharmacist help you to make your own decisions by providing you with information about the advantage and disadvantages of different treatments?

10 Is it based on what you want or can achieve, or what the pharmacist wants?

11 Can you explain in details how the counselling service given by the pharmacist can be further improved or enhanced?

12 Do you have access to the pharmacist if you need their assistance? which is better, to know appointments in advanced?

13 How was the information provided to you?

14 Give example what type of communication skills is needed to by the pharmacists to engage with you?
Pharmacists

How do you start the counseling session with your patients?

How do you treat your patients during your counselling sessions? Take time to bond with your patients?

Please explain how you communicate with your patients? How to make counselling more attractive?

Do you re-assess your patients' medication understanding? What type of questions do you ask your patients to assess their understanding?

How do you present yourself (body language) when facing your patients during counselling?

How do you encourage your patients to share ideas, discuss their feelings about the treatment plan and medications?

Are you sensitive towards your patients when giving information and instructions to them?

Do you support or accept your patients believe relating to diabetes and its medications? If yes, Why? If no, why?

Whose decision is the most important during counselling? Is it yours or the patients? Why?

Are you able to discuss and agree upon a treatment plan with your patients to reach the desired effect of treatments (mutual agreement)?

Do you help your patients to make their own decisions by providing them with information about the advantage and disadvantages of different treatments?

Is it based on what you want or can achieve, or what the patient can achieve?

Can you explain in details how the counselling service given by the pharmacists can be further improved or enhanced?

How does your patients access to you if they need your assistance? which is better, patients to know appointments in advanced?

How do you provide the information to your patients?

What type of communication skills is needed to engage with your patients? 
Table II. Themes, Sub-themes and Patient's/Pharmacist's Quotes

\begin{tabular}{|c|c|c|}
\hline Themes & Sub-Themes & Patient's/Pharmacist's Quotes \\
\hline \multirow[t]{5}{*}{\begin{tabular}{|l|} 
Establish \\
Rapport
\end{tabular}} & $\begin{array}{l}\text { Introduction and } \\
\text { greetings }\end{array}$ & $\begin{array}{l}\text { "Patient sometimes will feel stress why you asking me to enter the } \\
\text { (counselling) room specifically not at the counter giving them } \\
\text { medications. Of course I need to introduce myself and then I will explain } \\
\text { to them why they were asked to come in and giving them more } \\
\text { counselling."(Pharmacist 6) } \\
\text { "Pharmacist introduces him/herself and explained the reason for the } \\
\text { counseling clearly. They the pharmacists talk clearly and well." (Patient } \\
\text { 2) }\end{array}$ \\
\hline & Ice-breaking & $\begin{array}{l}\text { "Small talk because after they feel comfortable then only they will give } \\
\text { you the information." (Pharmacist } 1 \text { ) } \\
\text { "They are busy so they tend to be impersonal. So they will go straight to } \\
\text { the point explain the gist of it and then leave asking the question } \\
\text { sessions towards the end." (Patient 12) }\end{array}$ \\
\hline & $\begin{array}{l}\text { Background } \\
\text { check }\end{array}$ & $\begin{array}{l}\text { "First I will ask what the patient occupation is. Because by knowing } \\
\text { their occupation I can roughly know their lifestyle...... Then you can suit } \\
\text { your counselling point based on the occupation." (Pharmacist 3) } \\
\text { "Sometimes the pharmacists treated us as if we do not know anything } \\
\text { about high blood sugar. Nowadays these things can be googled. I feel } \\
\text { some of the pharmacists did not study on patients background before } \\
\text { counselling." (Patient 1) }\end{array}$ \\
\hline & $\begin{array}{l}\text { Pharmacists' } \\
\text { Attitude }\end{array}$ & $\begin{array}{l}\text { “Because patient always see our eyes. So I make sure I engage with the } \\
\text { patient.... I don't speak too fast, too slow.” (Pharmacist 1) } \\
\text { "Explain one by one. It's about me. They look at me when they talk. They } \\
\text { will talk slowly and explain well." (Patient 2) }\end{array}$ \\
\hline & \begin{tabular}{|l} 
Pharmacists' \\
Motivation
\end{tabular} & $\begin{array}{l}\text { “Some pharmacists just want to give information. I feel the recent one } \\
\text { the pharmacists are motivated to counsel." (Patient 11) } \\
\text { "I just feel happy seeing their (the patients) sugar level is control, be it } \\
\text { a little bit or a lot of difference. (Pharmacist 6) }\end{array}$ \\
\hline \multirow[t]{4}{*}{\begin{tabular}{|l|} 
Obtain \\
Information
\end{tabular}} & Attentiveness & $\begin{array}{l}\text { "we make sure the patients feel comfortable, so we don't do } \\
\text { (counselling) at the counter, we don't do (counselling) anywhere but } \\
\text { only in this room." (Pharmacist 1) } \\
\text { "(The pharmacist) Give full attention. They have asked about me." } \\
\text { (Patient 2) }\end{array}$ \\
\hline & $\begin{array}{l}\text { Interactive- } \\
\text { communication }\end{array}$ & $\begin{array}{l}\text { "I am not sure maybe they are not willing to interact. Some they don't } \\
\text { give respond. They just nodding their head." (Pharmacist 7) } \\
\text { "I feel the opportunity to discuss is there. They always give me the } \\
\text { opportunity, but I am the one who talk less." (Patient 11) }\end{array}$ \\
\hline & Time-factor & $\begin{array}{l}\text { "I don't have enough time. I want to finish the session fast. If I have the } \\
\text { time may be I will ask more questions. (Patient 15) } \\
\text { "Then I won't force them I will review later. If I see that they are in a } \\
\text { rush I will assess some main points only. Then next time will assess } \\
\text { what I want. I don't force them." (Pharmacist 2) }\end{array}$ \\
\hline & \begin{tabular}{|l|} 
Re-assess \\
patients' \\
understanding
\end{tabular} & $\begin{array}{l}\text { "Usually after I do counseling, I will ask the patients to repeat back what } \\
\text { I teach. See what are the answers. From there I know whether they } \\
\text { understand." (Pharmacist 7) } \\
\text { "If I don't understand they will ask again. Ask me to ask without any } \\
\text { hesitations about medications. They will teach me until I fully } \\
\text { understood." (Patient 8) }\end{array}$ \\
\hline
\end{tabular}


Potential codes were taken during transcribing and further categorized into themes and subthemes. A combination of computer software ATLAS.ti and hand-written methods were used in the mind mapping to assist with the development of the themes (Sandelowski, 2010). An inductive process was used to code and recode for common phrases and same ideas. Codes that were not relevant were excluded and similar codes were placed under respective themes and subthemes. Further discussions were held to discuss with the research team to finalize the themes and subthemes. The consistency and reliability of coding and themes was ensured and consensus was obtained from all researchers. The research team mutually agreed upon the quotes representing the themes.

\section{RESULT AND DISCUSSION}

The mean age of the patients and duration of their diabetes were 58 (SD 8.7) years and 11 (SD 4.7) years, respectively. The mean of HbA1c was 9.04\% (SD 1.76). All patients who took part in the study were on oral hypoglycaemia agents and/or insulin. The average frequency of practice experience of the pharmacists with the patients in this study was 2 to 5 times per patient. The average contact hours spent for the counselling by the DMTAC pharmacist is less than 5 hours per week.

The thematic qualitative analysis identified the following themes associated with pharmacistpatient engagement: establish rapport, getting information to explore the patient problems, building relationship, explanation and planning and closing the session (Refer Table II for themes, subthemes and the supportive quotes). A conceptual framework of pharmacist active engagement in diabetic education (Figure 1). The sub-themes and themes were further categorized into skills in aiding patient participation and target goals/patient satisfaction.

\section{Theme 1: Establish rapport}

Generally the pharmacists and patients had narrated that the initial background check such as greeting the patients, asking for patients' names, patients' daily activities, occupation and lifestyle was performed.

Subtheme 1a: Introduction and greetings

Most patients narrated that the pharmacists do greet, introduce themselves and explain the reason for the counselling. However, some reported that they couldn't remember much about the pharmacists introducing themselves. The pharmacists would go straight into the core counselling details. Most patients complimented that the pharmacist are dedicated and professional. Pharmacists narrated that they would always introduce and greet patients and explain the reason for the counseling.

\section{Subtheme 1b: Ice breaking}

Ice breaking or bonding with the patients are the time spent by the pharmacists and patients before going into the core counselling details. Some pharmacists explained that they would engage into small talks with the patients whenever time permits. However, some patients felt that the pharmacists can be more engaging when talking to them.

\section{Subtheme 1c: Background check}

Some pharmacists made effort in screening the patient's background such as occupation, education level and the patients existing knowledge and understanding. Sometimes the patients felt that the pharmacists are merely just instructing them without having much understanding about what are the real problems and needs of the patients.

\section{Subtheme 1d: Pharmacists' Attitude}

Patients generally felt the pharmacists showed a good gesture and did not get distracted with book or computers. As for the pharmacists they also reported that they showed good attitude towards their patients.

\section{Subtheme 1e: Pharmacist's motivation}

The pharmacists narrated that some of the motivation factors for them to do counselling are improvements' in patients' blood sugar level and quality of life. Most patients felt that pharmacists were genuine and motivated to help them.

\section{Theme 2: Obtain Information}

Patients narrated that they are normally able to provide the necessary information to the pharmacists during counseling sessions. However, some pharmacists said that due to language issues they faced some difficulties in obtaining information from the patients.

\section{Subtheme 2a: Attentiveness}

The patients generally had said that the pharmacists paid full attention to them during counselling and asked a lot of questions about them. Pharmacists said, the patients were counselled in privacy with full attention.

\section{Subtheme 2 b: Interactive-communication}

Patients did face some difficulties in communicating with the pharmacists. They held back and tried not to ask questions. Pharmacists on the other hand felt that some patients responded and communicated while some do not despite their effort in making them to talk. 
Table 2a. Themes, Sub-themes and Patient's/Pharmacist's Quotes

\begin{tabular}{ll}
\hline Themes & Sub-Themes \\
\hline Establish & Introduction and \\
Rapport & greetings
\end{tabular}

Ice-breaking

Patient's/Pharmacist's Quotes

"Patient sometimes will feel stress why you asking me to enter the (counselling) room specifically not at the counter giving them medications. Of course I need to introduce myself and then I will explain to them why they were asked to come in and giving them more counselling."(Pharmacist 6)

"Pharmacist introduces him/herself and explained the reason for the counseling clearly. They the pharmacists talk clearly and well." (Patient 2)

Background check

"Small talk because after they feel comfortable then only they will give you the information." (Pharmacist 1 )

"They are busy so they tend to be impersonal. So they will go straight to the point explain the gist of it and then leave asking the question sessions towards the end." (Patient 12)

"First I will ask what is the patient occupation. Because by knowing their occupation I can roughly know their lifestyle..... Then you can suit your counselling point based on the occupation." (Pharmacist 3)

"Sometimes the pharmacists treated us as if we do not know anything about high blood sugar. Nowadays these things can be googled. I feel some of the pharmacists did not study on patients background before counselling." (Patient 1)

Pharmacists' Attitude "Because patient always see our eyes. So I make sure I engage with the patient.... I don't speak too fast, too slow." (Pharmacist 1)

"Explain one by one. It's about me. They look at me when they talk. They will talk slowly and explain well." (Patient 2)

Pharmacists' "Some pharmacists just want to give information. I feel the recent Motivation one the pharmacists are motivated to counsel." (Patient 11)

"I just feel happy seeing their (the patients) sugar level is control, be it a little bit or a lot of difference. (Pharmacist 6)

Building Sharing of Ideas
Relationship

"They just ask me some opinions..... but not really share their thoughts." (Pharmacist 7)

"One way discussion is better. Because our idea, sometimes could be right, could be wrong. They (the pharmacists) know better." (Patient 6)

Emotions, "I will make them feel comfortable by speaking in a relationship and trust friendly....Show empathy...You don't straight away blame them. (Pharmacist 1)

"Because pharmacists are professionals. Have to trust, if don't trust what to do." (Patient 9)

Sensitiveness "I will ask patient before I decide anything for them. Can you do it? Some patient said no I can't. I don't have time to do this. So we do other adjustment. (Pharmacist 6)

"Do they care? You know you put into a situation where half way into the conversation you want to get out." (Patient 12)

Support and Believe "I would see whether their believes are correct or not. If their believes are medically correct I would support if not I would say how can I correct them help them to correct their thinking." (Pharmacist 1)

"Even if I have the knowledge to share, they (pharmacists) don't want to accept. By right they should let us share our knowledge." (Patient 1) 
Table 2b. Themes, Sub-themes and Patient's/Pharmacist's Quotes

\begin{tabular}{|c|c|c|}
\hline Themes & Sub-Themes & Patient's/Pharmacist's Quotes \\
\hline \multirow[t]{2}{*}{$\begin{array}{l}\text { Explanation } \\
\text { and Planning }\end{array}$} & Making decisions & $\begin{array}{l}\text { "I make sure they agree. No matter how I counsel them or how } \\
\text { I try to help if in the end they just listen left ear and then come } \\
\text { out right ear is not helping them. I make sure they } \\
\text { agree."(Pharmacist 1) } \\
\text { "The decisions taken by the pharmacists for me, I can accept it } \\
\text { full heartedly." (Patient } 7 \text { ) }\end{array}$ \\
\hline & $\begin{array}{l}\text { Mutual } \\
\text { agreement/two- } \\
\text { way discussions }\end{array}$ & $\begin{array}{l}\text { "Best way is two ways communications. Get confidence. } \\
\text { Patients' feels that you are helping them. "(Pharmacist } 7) \text {. } \\
\text { "I think the pharmacists are talking about the same thing. They } \\
\text { repeat the same stuffs. It's boring. Unless you give me the new } \\
\text { knowledge." (Patient 1) }\end{array}$ \\
\hline \multirow[t]{3}{*}{$\begin{array}{l}\text { Closing the } \\
\text { session } \\
\text { (Others) }\end{array}$} & $\begin{array}{l}\text { Accessibility to } \\
\text { pharmacists }\end{array}$ & $\begin{array}{l}\text { "...... before I end every session I always tell them any problem } \\
\text { at all they can always come back to our pharmacy counter not } \\
\text { necessarily when they no specific time.." (Pharmacist 1) } \\
\text { "No I don't have any access (to the pharmacist). I think that } \\
\text { should be given to everyone. Any problem, come and see them } \\
\text { (pharmacist) rather than seeing the doctor." (Patient } 4 \text { ) }\end{array}$ \\
\hline & $\begin{array}{l}\text { DMTAC } \\
\text { Appointments }\end{array}$ & $\begin{array}{l}\text { "A lot of time when we give appointments previously patient } \\
\text { did not turn up. So the way we do is when patient come to } \\
\text { collect medications we ask the patient to go for the DMTAC } \\
\text { counselling." (Pharmacist 2) }\end{array}$ \\
\hline & & $\begin{array}{l}\text { "Sometimes after } 3 \text { to } 4 \text { months when collect medicine they } \\
\text { will ask me for counselling. Appointment dates were not given. } \\
\text { No recording of the dates." (Patient } 2 \text { ) } \\
\text { "They did give me I think a booklet, appointment } \\
\text { card."(Patient 12) }\end{array}$ \\
\hline
\end{tabular}

\section{Subtheme 2c: Time Factor}

The patients' narrated that they did not ask many questions to the pharmacists because they were in a rush for other things. Therefore, they wanted the counselling session to end fast. Pharmacists also counsel patient depending on patients' willingness to stay for the sessions. Some pharmacists mentioned that they rush the counseling as they have other patients waiting or other tasks to perform.

Subtheme 2d: Re-assess patients' understanding All pharmacists mentioned that they assessed the patients' understanding towards the treatment plan or injection techniques. Patients also mentioned that re-assessment was performed by the pharmacists each time during the counseling.

\section{Theme 3: Building Relationship}

Patients and pharmacists were asked questions whether the patients were able to share their ideas, discuss how they felt about the treatment plans and medications, pharmacists' sensitiveness, accepting or believing in patients relating to diabetes and its medications.

\section{Subtheme 3a: Sharing of ideas}

Generally patients' prefers input from the pharmacists as they felt the pharmacists being the healthcare professionals and hence they would prefer to follow what the pharmacists shared. Many patients mentioned that they prefer not to share their ideas or opinions because they felt that the pharmacists are experts in drugs so they should know better. Pharmacists narrated that most of the time the patients will listen to them and ask some questions about medications but not so much on sharing ideas.

\section{Subtheme 3b: Emotions, relationship and trust}

Pharmacists had worked on getting the patients trusts so that patients will share information and hence it will be easier for the pharmacists to build the relationship with the patients. Patients generally had good trust in pharmacists in terms of the treatment plan, even if some patients are not comfortable with the plan. 


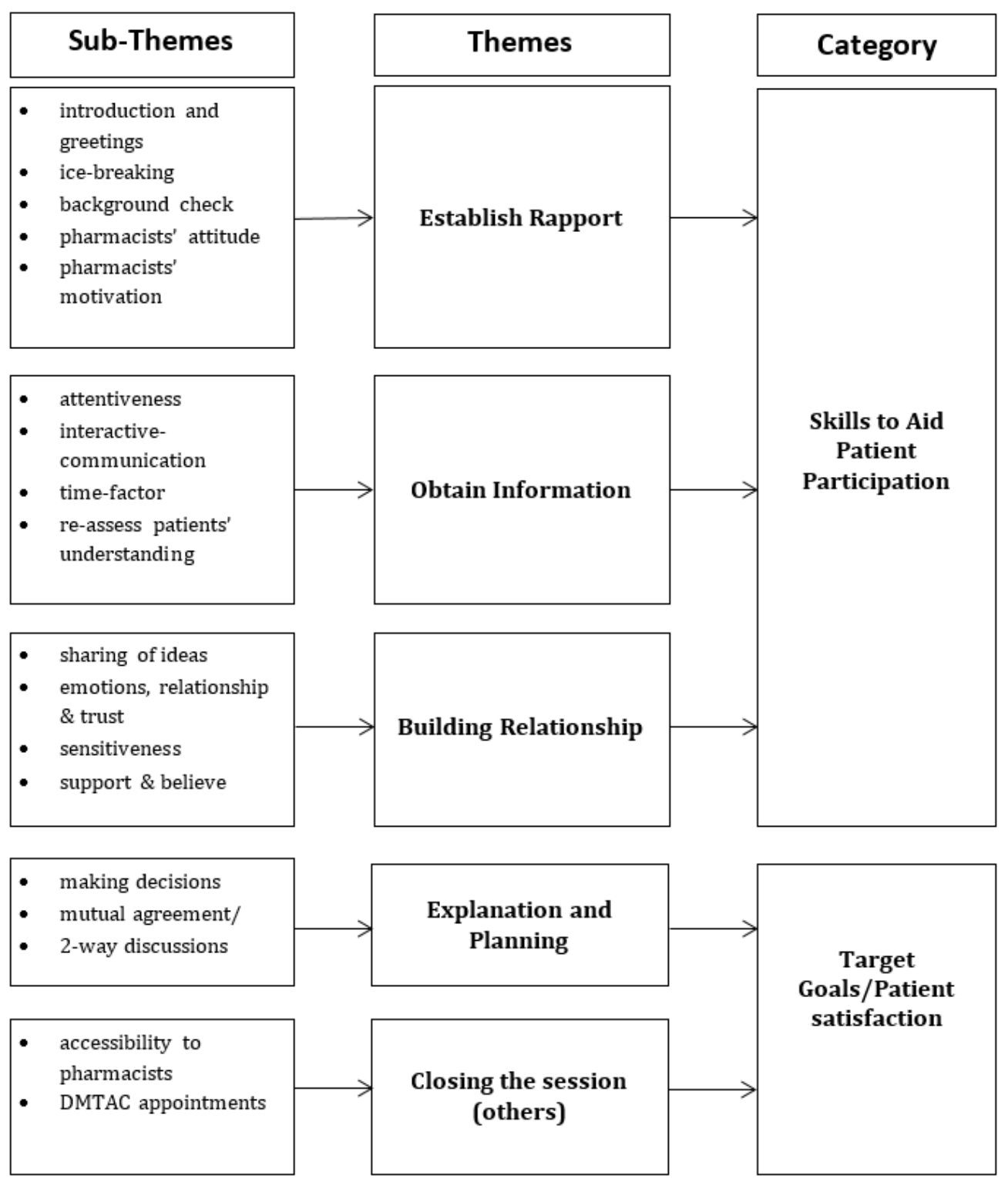

Figure 1: Conceptual framework of pharmacist active engagement in diabetic education

\section{Subtheme 3c: Sensitiveness}

Pharmacists when giving information and instructions to patient during the counseling looked into patients' sensitiveness as well. Patients generally said they felt comfortable with the information or instructions received. However, some patients did felt that the pharmacists are not sensitive enough towards them.

\section{Subtheme 3d: Support and believe}

Pharmacists said that they normally encourage patients to share their ideas or believe to them during discussion. However, their ideas will be corrected if they feel the patients believe is merely a myth. Patients on the other hand felt that pharmacists may not accept their ideas and believes and choose to keep silent.

\section{Theme 4: Explanation and Planning}

Pharmacists said that they would explain and seek patients' acceptance of the plan as much as possible. While patients said they normally would agree to the plan that was given to them as it is deemed the best treatment option available.

Subtheme 4a: Making decisions

Most pharmacists informed that patients are the ultimate decision maker. If they disagree to the plan that was given to them, the patients will 
eventually refuse to follow. However, some pharmacists informed that they should decide for their patients. While, some patients said that they should be the decision maker while some said they would let the pharmacists to decide.

\section{Subtheme 4b: Mutual agreement/two-way discussions}

According to the pharmacists normally they will engage patients into discussion. However, due to the limited resources sometimes patients did not have many options in the treatment plan and hence patients are not offered many options in the treatment plan. Patients' felt that the counseling can be boring as it did not have much variety and content in the discussions.

\section{Theme 5: Closing the session (Others)}

Most DMTAC pharmacists said that at the end of the session, they would summarize the session and discuss with patients about the next appointments and how to reach or contact them if the patients have any questions.

\section{Subtheme 5a: Accessibility to Pharmacists}

According to the pharmacists they inform patients on how to reach them if they need assistance. However, some patients said that they were not aware of the appointment dates and were unsure if the pharmacists have informed them that they can meet them if they have any questions.

\section{Subtheme 5b: DMTAC Appointments}

Pharmacists explained the difficulties in making patients' turn up for their counseling sessions and some patients said they were are unaware of their appointments.

Effective treatment plans may be developed if the pharmacists are able to encourage patients to fully participate in the disease management discussion. This strategy is also known as active engagement or patient-centred communication approach. Modern medicine is changing from a purely biomedical model of care to a holistic framework to describe and explain how illness is the result of the interplay of biological, psychological, social factors and individual healthrelated behaviours (Naughton, 2018.).

Pharmacists should plan and allocate sufficient time for the pre-screening process such as knowing patients background such as education level, needs, emotional state, medical, knowledge and time factor. It is known that large numbers of patients per pharmacist or the patient's eagerness for fast discharge can be the major barriers to effective counselling (O'Donnell et al., 2006). The pharmacists are often straightforward and mostly using close ended questions (Greenhill et al., 2011).
Nevertheless, patients' may not prepare or have the state of mind to fully engaged into the counselling sessions without the pharmacists understanding the emotions, needs and background of the patients. It is important to use both open and close ended questioning techniques when establishing initial rapport with patients and gathering of information (Fisher, 1992). Hence, in order to get the patients' attention and full engagement the sessions needed to be tailored-made for each patient.

Pharmacists normally meet patients on the same day as the medical diabetes clinic. Patients would have spent an average of three hours to see the doctor and then proceed to the pharmacy to collect the medications. Patients tend to be reluctant if they were in a rush to work or to be back home. A study conducted in Malaysia suggested that primary clinics need to improve their waiting time and facilities for patients' comfort (Ahmad et al., 2017).

They were taken by surprise at times when they were asked to attend the counseling session. Some patients were aware of the appointments with the pharmacists as the pharmacists verbally told them at the end of the previous counselling session and the counselling date was written on the appointment card. Patients generally preferred that they were pre-informed about the counselling sessions. This would enable them to allocate time for the counselling sessions and be mentally prepared for the session.

A well-tailored counselling program that took into consideration the patients' educational status might help in enhancing medication knowledge among those with lower educational level. A scheduled continuous patient counselling will also lead to better medication knowledge (Alkatheri \& Albekairy, 2013). Patients are willing to take part in the discussion and decision-making. Hence, it is important for the pharmacists to know the patients' educational background and to understand their areas of concern and needs, knowledge in managing diabetes and the medications.

The pharmacists approached the patients genuinely to help the patients in managing their diabetes and medications. Generally, patients felt comfortable with the pharmacist's approach. After pre-screening, the pharmacists should spend some time for icebreaking before going into the core details of the counselling. The communication skills for exploration of the patient's problems involves attentive listening, open ended to close ended 
questioning style, picking up cues, appropriate use of language, time framing, facilitative responses, additional skills for understanding patients' perspective (Kurtz et al., 2003). Findings from this study showed that pharmacists did make good efforts to make the patients felt comfortable. It is important to the patients where the healthcare providers show courtesy, treat with respect and carefully listen to them (ACSQHC, 2011; Osborn, 2011).

Pharmacists should establish good rapport with the patients. Effective medications taking can be rendered ineffective if patients struggled to make behaviour changes. Methods employed by the pharmacists to actively engaging the patients has been shown to be an effective counselling method (Ells \& Sherman, 2013). One of the very important aspects of getting patient actively engaged in the counselling is communication skills. In this study, the pharmacists assessed patients' understanding during the counselling sessions or at the end of the sessions.

Majority of the patients passively listened to what the pharmacist have to say. Some patients felt that their ideas could be wrong and hesitated to share with the pharmacists. Pharmacists may not realize that they were highly focusing to deliver the core knowledge about diabetes and medications to patients, and forgotten to play the active engaging role in the counselling sessions. Healthcare that is focused on providing services that are patientcentered must ensure that patients' voice and experience of healthcare provision is increasingly being sought after from an organizational quality improvement perspective (ACSQHC, 2011; Osborn, 2011).

This study showed that pharmacists during the counselling sessions would explain to the patients about the treatment plan after a comprehensive discussion and mutually agreement. Patients should not feel they were forced to follow the plans that they were not comfortable with (Kassam et al., 2008). Showing empathy and listen to what the patients have to say before making any conclusion is important. The core factor was to gain trust from the patient and to go into a much depth conversation with the patients. (McCabe, 2004).

A survey showed that only $44 \%$ of the pharmacists responded that they continued their professional development in communication skills after their undergraduate degree (Jalal et al., 2018). Patient-centred care is patient-provider collaborated effort to maximize the consultation or counseling and not a one-side approach $(\mathrm{Ng}$ et al., 2020). This is in line with Communication Accommodation Theory (CAT), which defines as behavioral or communicative changes or adjustments made by human while interacting with others (Giles, 2016). A study utilizing CAT reported that pharmacists' communication could be improved from the start of session by asking openended questions to invite patients' input and empower the patients to ask questions related to their medications (Chevalier et al., 2017). Another communication framework known as "The FourHabit Model (FHM)" may also be adapted in patient education. The FHM covers 4 main elements, namely invest in the beginning to establish rapport and build trust rapidly, elicit the patient's perspective to facilitate the effective exchange of information, demonstrate empathy to show care and concern, and invest in the end to increase adherence and positive health outcomes. Study applying the FHM in pharmacy education improved communication and relationship between pharmacy student and patients (Grice et al., 2012). These theories proved to be effective to improve communication skills and relationship with patients. It is proposed that the future DMTAC training may include a module on pharmacists' active engagement skills; for example, by employing motivational interviewing or patientscentered care skills the pharmacists' active engagement towards their patients can be further enhanced.

\section{LIMITATIONS}

The current study is limited to urban setting. The findings may be different if the primary setting covers non-urban areas due to differences in sociodemographic characteristics such as level of literacy and access to health services. Time commitment from the patients may differ the way and depth of their answer so there might be missing codes which consequently affecting the sub-themes. The interviewer may subconsciously give subtle clues in with body language and tone of voice. Data usually skewed towards the interviewer's own opinion, prejudices and values. The subject consciously or subconsciously gives response that they think that the interviewer wants to hear. Nevertheless, to minimize the effect of these limitations, the interviewer introduced her/himself as a researcher and not as a healthcare provider. The patients were assured to freely give their opinions without any fear of being judged or penalized. 


\section{CONCLUSION}

This study identified areas of active engagement approach namely, effective communication skills, shared decision-making, motivational interviewing skills, and emotional intelligence skills. These support the need for continuous professional training for pharmacists in the area of active engagement in patient education. Module for pharmacists' training should adapt the subthemes identified in this study. Assessments on the level of active engagement practice by the counseling pharmacists should be evaluated periodically to improve quality of the service.

\section{ACKNOWLEDGEMENTS}

The authors wish to thank the Jabatan Kesihatan Wilayah Persekutuan and Putrajaya for allowing this study to be conducted at their premises.

\section{REFERENCES}

Ahmad, BA., Khairatul, K., \& Farnaza, A. (2017). An assessment of patient waiting and consultation time in a primary healthcare clinic. Malaysian Family Physician, 12(1), 1421.

Alkatheri, AM., \& Albekairy, AM. (2013). Does the patients' educational level and previous counseling affect their medication knowledge? Annals of Thoracic Medicine, 8(2), 105-108.

Australia Commission on Safety and Quality in Health Care (ACSQHC). (2011). Patientcentred care: Improving quality and safety through partnerships with patients and consumers.

Bachmann, C., Abramovitch, H., Barbu, CG., Cavaco AM., Elorza, RD., Haak, R., Loureiro, E., Ratajska, A., Silverman, J., Winterburn, S., \& Rosenbaum, M. (2013). A European consensus on learning objectives for a core communication curriculum in health care professions. Patient Education and Counseling, 93(1), 18-26.

Chevalier, BAM., Watson, BM., Barras MA., \& Cottrell, WN. (2017). Investigating strategies used by hospital pharmacists to effectively communicate with patients during medication counselling. Health Expectations, 20, 1121-1132.

Ells, AW., \& Sherman, J. (2013). Community and Clinical Pharmacy Services: A step by step approach. Google eBook, pp.349.

Fisher, RC. (1992). Patient education and compliance: A pharmacist's perspective. Patient Education and Counseling, 19(3), 261-271.

Giles, H., (2016). Communication Accommodation Theory. The International Encyclopedia of Communication Theory and Philosophy, pp.1-7.

Graffigna, G., Barello, S., Libreri, C., \& Bosio, CA. (2014). How to engage type-2 diabetic patients in their own health management: Implications for clinical practice. BMC Public Health, 14(1), 2-12.

Greenhill, N., Anderson, C., Avery, A., \& Pilnick, A. (2011). Analysis of pharmacist-patient communication using the Calgary-Cambridge guide. Patient Education and Counseling, 83(3), 423-431.

Grice GR., Gattas NM., Sailors J., Murphy, JA., Tiemeier, A., Hurd, PH., Prosser, T., Berry, T., \& Duncan, W. (2013). Health literacy: use of the Four Habits Model to improve student pharmacists' communication. Patient Education and Counseling, 90(1), 23-28.

Guariguata, L., Whiting, DR., Hambleton, I., Beagley, J, Linnenkamp, U., \& Shaw, JE. (2014). Global Estimates of Diabetes prevalence for 2013 and Projections for 2035. Diabetes Research and Clinical Practice, 103(2), 137-149.

Jalal, Z., Cox, A., Goel, N., Vaitha, N., King, K., \& Ward, J. (2018). Communications Skills in the Pharmacy Profession: A Cross Sectional Survey of UK Registered Pharmacists and Pharmacy Educators. Pharmacy, 6(4), 1-14.

Kassam, R., Volume-Smith, C., \& Albon, SP. (2008). Informed shared decision making: An exploratory study in pharmacy. Pharmacy Practice, 6(2), 57-67.

Kurtz, S., Silverman, J., Benson, J., \& Draper, J. (2003). Marrying content and process in clinical method teaching: enhancing the Calgary-Cambridge guides. Academic Medicine 78(8), 802-809.

McCabe, C. (2004). Nurse-patient communication: An exploration of patients' experiences. Journal of Clinical Nursing, 13(1), 41-49.

Pharmacy Services Division:Ministry of Health Malaysia. (2014). Protocol Medication Therapy Adherence Clinic: Diabetes (DMTAC), Second Edition, pp.1-28.

Naughton, CA. (2018). Patient-Centered Communication. Pharmacy (Basel), 6(1), (18), 1-8. 
Ng, YK., Shah, NM., Loong, LS., Pee, LT., Hidzir, SAM., \& Chong, WW. (2018). Attitudes toward concordance and self-efficacy in decision making: A cross-sectional study on pharmacist-patient consultations. Patient Preference and Adherence, 12, 615-624.

Ng, YK., Shah, NM., Loong, LS., Pee, LT., \& Chong, WW. (2020). Patient-centred care in the context of pharmacy consultations: A qualitative study with patients and pharmacists in Malaysia. Journal of Evaluation in Clinical Practice, (online ahead of print), https://doi.org/10.1111/jep.13346

O'Donnell, DC., Brown, CM., \& Dastani, HB. (2006). Barriers to counseling patients with obesity: A study of Texas community pharmacists. Journal of the American Pharmacists Association, 46(4), 465-471.

Osborn, R. (2011). The Commonwealth Fund International Health Policy Surveys. pp.1-38.

Sandelowski, M. (2010). What's in a name? Qualitative description revisited. Research in Nursing and Health, 33(1), 77-84.

Saunders, B., Sim, J., Kingstone, T., Baker, S., Waterfield, J., Bartlam, B., Burroughs, H.; \& Jinks C. ( 2018). Saturation in qualitative research: exploring its conceptualization and operationalization. Quality and Quantity,
52(4), 1893-1907.

Shortell, SM. (2013). Bridging the divide between health and health care. Journal of the American Medical Association, 309(11), 1121-1122.

Snowden, A., Martin, C., Mathers, B., \& Donnell, A. (2014). Concordance: A concept analysis. Journal of Advanced Nursing, 70(1), 46-59.

Sufiza Ahmad, N., Ramli, A., Islahudin, F., \& Paraidathathu, T. (2013). Medication adherence in patients with type 2 diabetes mellitus treated at primary health clinics in Malaysia. Patient Preference and Adherence, 7, 525-530.

Wilson, SR., Strub, P., Buist, A S., Knowles, S B., Lavori, PW., Lapidus, J., Vollmer, W.M., \& Better Outcomes of Asthma Treatment (BOAT) Study Group. (2010). Shared treatment decision making improves adherence and outcomes in poorly controlled asthma. American Journal of Respiratory and Critical Care Medicine, 181(6), 566-577.

Zuckerman, B., Margolis, PA., \& Mate, KS. (2013). Health Services Innovation: The time is now. Journal of the American Medical Association, 309(11), 1113. 